\title{
Convergence in Sub-Saharan Africa: a nonstationary panel data approach
}

\author{
SUZANNE K. MCCOSKEY
}

Given the development of time series econometrics and nonstationary data analysis, St. Aubyn (Empirical Economics, 24, 23-44, 1999) demonstrates a new paradigm for testing income convergence, or better denned, income stability, namely testing the stationarity of pair-wise income differentials. In this paper, a panel data set of Sub-Saharan African countries is constructed and panel cointegration and unit root tests are used to investigate the convergence properties of incomes and standards of living within Africa. Overall, little evidence is found to substantiate claims of convergence across Africa, although in some cases, smaller convergence clubs within Africa may be found. In addition the use of nonstationary panel data techniques is proposed for the testing and establishing of coherent convergence clubs.

\section{INTRODUCTION}

Ever since the work of Barro (1991) and Barro and Sala-I-Martin (1992) came onto the stage in economics, income convergence has been a particularly hot area for economic debate. Early studies ${ }^{1}$ included the aforementioned articles by Barro and Sala-I-Martin (1992) on convergence of incomes in US states; Barro and Sala-I-Martin (1991) on the convergence of incomes in the US states and European regions (again discussed in Sala-I-Martin, 1996); and Barro (1991) on the convergence of income across countries. The overall conclusion of these articles, in the case of the relatively homogeneous US and Europe, was that there was a pattern of convergence across the sample, and in most instances the rate of convergence was roughly $2 \%$. In the case of the cross national, more heterogeneous study, convergence could only be established when it was conditioned on such variables as human capital and fertility. Using the Solow growth model, Mankiw et al. (1992) also investigate income convergence for a cross-section of countries. They also find that within the Solow growth model framework, convergence among countries is possible when population growth and capital accumulation are held constant. Again they find some evidence for conditional convergence. However, even these growth and convergence studies were limited in the way they accommodated the time dimension. For the most part, they use cross-section data sets or cross-sections constructed from observations averaged over time. One exception is the panel data approach discussed in Islam (1995).

More recent work has attempted to use more sophisticated nonstationary time series tools to approach this problem. Using nonstationary time series tools allows for a more well-developed understanding of the actual path of the series involved, an understanding which can be crucial when one seeks to understand potential convergence over time. These articles include Quah (1996a), Quah (1996b), and Quah (1996c), Lee et al. (1997), Pedroni (1997), St. Aubyn (1999), and McCoskey and Kao (1999). As incomes have often tested nonstationary, or 1(1), the time series tools can also avoid the potential for spurious regressions, see for example Phillips (1986).

Quah (1996b) and (1996c) taken together provide a very different view of convergence possibilities (as compared to the work by Barro and Barro and Sala-I-Martin.) Quah (1996b) calls seriously into the question the 2\% convergence rate using Monte Carlo experiments and Quah (1996b) finds that passage of a poor country into the set of richer country is extremely unlikely. Quah (1996a) continues further with the idea of going beyond the strict homogeneous cross-section and discusses the understanding of the distribution of the entire cross-section. He finds that cross-sections, or countries, have incentives to form coalitions of 'like' partners and that there exist very serious incentives to fragment within the overall set of countries. The result means that the income distribution can stratify and the gap between rich and poor increase. Thus, convergence will only take place within relatively homogeneous convergence clubs. Two suggestions for club formation would be to group countries within the context of their most important trading partners or their geographic location.

This question of convergence clubs and regional homogeneity is perhaps unresolved with respect to Africa. Although there are surely some regional and national differences, geographic proximity and cross-national economic interdependence bring into question the possibility that this continent will grow or falter as one. Certainly in the popular press such opinions have been held, especially with regards to The Economist which has recently featured Africa on two separate covers.

\footnotetext{
${ }^{1}$ There is also the earlier work by Baumol (1986) which, while discussing convergence, did not lead to such an outpouring of other research work.
} 
The first is entitled 'The Risk in Africa: Robert Mugabe threatens more than just Zimbabwe' (22 April). ${ }^{2}$ The second cover features an outline of Africa with a young man armed with a handheld RPG (rocket propelled grenade). The title reads 'The hopeless continent' (13 May). Clearly outsiders' perceptions are that Africa is bound together by some common realities.

Lee et al. (1997) return to the Solow growth model framework. They apply panel data techniques and argue for heterogeneous panel data specifications that would allow for different growth rates across countries. They find that assuming homogeneity and using crosssection data to investigate convergence can have serious implications econometrically. Pedroni (1997) and McCoskey and Kao (1999) continue with use of heterogeneous panel techniques and investigate the impact of human capital and urbanization, respectively, on growth, although not specifically addressing the convergence question.

The framework from St. Aubyn (1999) is used as the underlying framework for this paper. The definition of convergence is taken as the stationarity of the difference of two series that are suspected of converging. In this case the difference of two measures for income for two different countries must be taken. As St. Aubyn (1999) explains such stationarity should encompass the 'beta-convergence' as proposed by Barro and Sala-I-Martin $(1992,1995) .{ }^{3}$ Although not specifically discussed, this analysis requires two major assumptions:

(1) the difference itself should not be allowed to be trend-stationary as a trend would mean a potential positive growth in the difference over time; and

(2) the two initial series should themselves be nonstationary (thus giving the test of stationarity of the difference some meaningful interpretation). Therefore the test of stationarity of the differences is conducted allowing only for the unique, known, cointegrating vector of $(1,0,-1)$.

St. Aubyn (1999), as Quah (1993), and Durlauf and Johnson (1992), uses convergence clubs in his analysis. In order to construct the appropriate differences a 'club' of similar countries is chosen and then a 'leading series' is identified. All of the other members of this club are then compared to the leading series, i.e. their series will be differenced from the leading member's series. In fact, the choice of the leader is then crucial. In his study, St. Aubyn uses the US as his leading series. In this paper, panel data tests are proposed as being superior to this methodology as using a panel test allows the researcher to test all possible combinations and therefore not specify a leader. Thus all potential members of the club are treated symmetrically without the possibility of bias introduced with the selection of the club leader.

St. Aubyn uses both the Augmented Dickey-Fuller (and Dickey-Fuller) unit root tests as well as a test using the Kalman Filter to test the null hypothesis of no convergence (i.e. nonstationarity of the difference). He uses a data set of developed countries ${ }^{4}$ for the years 1890-1989. In general, the Kalman Filter test performs better as it is much more likely to reject the null hypothesis of no convergence. For the entire sample (1890-1989), the ADF is only able to reject the hypothesis of no convergence for France, Australia, Belgium, the Netherlands, and Switzerland. The Kalman Filter test, on the other hand, is able to reject the null hypothesis (at the 1\% confidence level) for the entire set of countries.

In this paper, the 'convergence club' of countries is a maximum set of 37 countries from Sub-Saharan Africa. ${ }^{5}$ Instead of a single series test of a pair-wise difference, however, panel data tests are used to pool the results. These tests can be used to establish clubs, by testing the overall convergence within the group as well as the question of whether or not a specific country belongs within the group by comparing it with all the established members and pooling the results. Thus, the low power of the ADF test in the strict time series case might be improved upon (just as in the use of the Kalman Filter test) as well as the flexibility of the test. Such a study should add to the paradigm of testing for club convergence as well as including developing country 'clubs' in the discussion of income convergence. ${ }^{6}$ In addition convergence for certain subgroups within Africa will also be tested, namely the South African Customs Union (SACU) and the Southern African Development Community (SADC).

\section{MODEL}

In this paper, several panel data tests will be conducted. In particular, panel data unit root tests will first be conducted on the original indicators of income and standard of living. These tests follow the procedure suggested in Im et al. (1997) [hereafter referred to as IPS]. Then panel data tests for cointegration will be conducted on different sets of club pairs. These tests will allow for heterogeneous cointegrating vectors and the test of the null hypothesis of cointegration from McCoskey and Kao (1998) and null hypothesis of no

\footnotetext{
${ }^{2}$ The North and South American edition for this date featured Elian Gonzales. The Mugabe cover was featured on the European/ African edition.

${ }^{3}$ However, St. Aubyn (1999) also identifies the problem case with such a definition; namely two series could converge and yet their difference be nonstationary.

${ }^{4}$ Canada, France, Germany, Italy, Japan, United Kingdom, Australia, Belgium, Denmark, Finland, Netherlands, Norway, Sweden, and Switzerland.
} 
cointegration as described by, among others, McCoskey and Kao (1999). Several different African club leaders will be used: Ivory Coast, Kenya, Malawi, Mauritius, Nigeria and South Africa. The choice of club leaders was primarily determined by the consistent availability of data. As all of the tests for cointegration are residual-based, estimation of the cointegrating vector can be conducted simultaneously to the testing. Thus, it will be possible to compare the vectors to that of the theoretically imposed vector of the difference of the two pairs.

Following St. Aubyn (1999) differences will then be constructed of the given series for each of the club experiments outlined above. This set of differences will be tested for difference stationarity (and not trend as discussed above) using again the test from IPS. In addition, all possible pair-wise combinations will be constructed. Thus, unlike in the strict time series case, in the last test no 'leader' need be identified; all countries in the club can be treated symmetrically.

\section{Model specifications}

1. Cointegration. The specification for cointegration, in the context of the panel tests, allows for heterogeneous slopes and intercepts. It is a simple bilateral relationship between the income (or other standard of living variables) of two countries over time. As discussed above, the specification allows for an intercept but not a time trend:

$$
y_{i t}=\alpha_{i}+\beta_{i} x_{i t}+\varepsilon_{i t}
$$

for all $i=1, \ldots, N$ and $t=1, \ldots, T$. $Y$ represents the series value for the leader country and $x$ for the follower county.

2. Unit Root Testing of Differences. The test for the unit root is performed on the difference of the two series and thus can be expressed as:

$$
d_{i t}=y_{i t}-x_{i t}
$$

Note that implicitly this is a construction whereby the cointegrating vector is restricted to $\{1,0,+1\}$. As the relationship is not estimated but rather imposed the unit root (and not cointegration) critical values are appropriate for ADF testing. In this case, to know whether the club as a whole is linked, the IPS test for unit roots in panel data is used.

\section{Econometric tests}

1. IPS Panel Data test of the null hypothesis of nonstationarity. The IPS test is constructed such that the null hypothesis is that all series in the panel contain a unit root against the alternative that none of the series contain a unit root. Thus while the panel may be heterogeneous, for example in lag order or exact value for the autoregressive parameter, all series must share the same stationarity properties. The test statistics uses as its foundation the average of all the individual series' ADF $t$-statistics to arrive at an average for the sample. Then using the Lindberg-Levy Central Limit Theorem, IPS demonstrate that when normalized by the appropriate mean and variance, their 'averaged' test statistic should converge to a standard normal distribution. In their paper, they provide the necessary means and variances, which depend not only on the time dimension but also on the lag order. Their z-bar statistic is given:

$$
z-b a r=\frac{\sqrt{N}(\text { avgt }-a n t)}{\sqrt{b n t}}
$$

'ant' and 'bnt' are constructed as averages of the appropriate means and variances across the panel. These moments can change with lag order and thus must be averaged across the panel as a whole.

\footnotetext{
${ }^{5}$ Angola, Benin, Botswana, Burkina Faso, Burundi, Cameroon, Chad, Comoros, Congo, Gabon, Gambia, Ghana, Guinea, Ivory Coast, Kenya, Lesotho, Madagascar, Malawi, Mali, Mauritania, Mauritius, Mozambique, Namibia, Niger, Nigeria, Reunion, Rwanda, Senegal, Seychelles, Somalia, South Africa, Swaziland, Togo, Uganda, Zaire, Zambia and Zimbabwe. Sierre Leone is used only in the case of government spending.

The latter contribution should not be overlooked. As one discussant in the 'General Discussion' section of the Barro and Sala-I-Martin (1991) Brookings Paper suggested, ‘. . in the light of the fact that this last decade has been one of backsliding for Africa and Latin America, how important [was it] that South Carolina was catching up to Connecticut'. [South Carolina and Connecticut are both States in the US.]
} 
2. McCoskey-Kao test of the null hypothesis of cointegration. The McCoskey and Kao (1999) panel data test of the null hypothesis of cointegration also exploits the cross-section dimension of the data by using the average of the LM test statistics of the null hypothesis of cointegration and again smoothing it across the cross-sections. The LM test statistic of the null hypothesis of cointegration is based on the time series test proposed by Harris and Inder (1994). This test is also presented in Shin (1994). The panel test allows for a heterogeneous crosssections, in particular this allows individual estimation of a potential cointegrating vector. Again the means and variances are necessary to exploit this smoothing and these are provided in the article. The LM - bar test statistic is given:

$$
L M-b a r=\frac{1}{N} \sum_{i=1}^{N}\left(\frac{\frac{1}{T^{2}} \sum_{t=1}^{T} S_{i, t}^{+2}}{\varpi_{t 1.2}^{2}}\right)
$$

which is based on the partial sum of consistently estimated errors terms and conditional variance. The LM-bar can then be normalized by the mean and standard deviation to form a test statistic which converges in distribution to a standard normal test statistic.

3. Test of the null hypothesis of no-cointegration. A panel test of the null hypothesis of no cointegration is also used for comparison. Two forms, based on the ADF and PP time series cointegration tests, are summarized in McCoskey and Kao (2000). In this paper, the averaged ADF form is used, and similar to the tests above takes the form:

$$
a d f-b a r=\frac{\sqrt{N}(\operatorname{avg}(a d f)-m e a n)}{\sqrt{\operatorname{var}}}
$$

The mean and variance depend on the number of $x$ regressors in the specification and are derived through Monte Carlo simulation. For more details, see McCoskey and Kao (2000). With one regressor the mean and variance used are -2.0261 and 0.6724.

4. Summary of tests. Since all of the tests allow for panel heterogeneity and are constructed by averaging individual test statistics and then normalizing by mean and variance, all of the final test statistics converge in distribution to standard normal random variables. In the case of the IPS and ADF-cointegration test, the rejection area is on the left tail of the distribution; in the case of the LMcointegration test, the rejection area is on the right tail of the distribution. Since all tests are based on averaging, there is a weakness in that they are susceptible to outliers. This can be seen especially when comparing the LM and ADF based cointegration tests. Unlike in the case of a single series, it is logically consistent that both tests can reject the null hypothesis. For example, the pooling nature of the test statistic means that not all members need to reject the null for the pooled version to reject. In fact, the sample may be split with outlier observations under each null which could cause 'dual rejection.' In such a case, the sufficient homogeneity of the series themselves may be called into question. In other words, the underlying assumption of the poolability of the panel may be violated. In addition, the method of testing 'both nulls' introduces a higher joint size of the test.

\section{Data}

The data for the study is taken from the Penn World Tables and the following series are tested.

\begin{tabular}{llll}
\hline $\begin{array}{l}\text { Series name } \\
(\mathrm{PWT})\end{array}$ & Description & Dates & $\begin{array}{l}\text { 'Club } \\
\text { size' }\end{array}$ \\
\hline$G$ & Government Share of GDP & $1960-1990$ & 30 \\
$K A P W$ & Capital Per Worker & $1965-1985$ & 11 \\
$O P E N$ & Openness of the Economy & $1960-1989$ & 37 \\
$R G D P L$ & Real GDP Per Capita & $1960-1989$ & 37 \\
$S T L I V$ & Standard of Living & $1970-1989$ & 11 \\
$R G D P W$ & Real GDP Per Worker & $1960-1989$ & 37 \\
\hline
\end{tabular}

$G$ is the government share of GDP measured in 1985 international prices. KAPW measures the capital stock per worker. OPEN is a measurement of exports added to imports as a fraction of GDP all measured in current international prices. RGDPL is a measure of real GDP per capita at 1985 international prices. STLIV measures consumption added to government expenditure (net military 
expenditures) as a\% of GDP. RGDPW measures real GDP per worker at 1985 international prices.

Thus, convergence in this study is taken beyond the simple definition of incomes to a broader investigation of the club. A summary of the data used for each series is given in Table 1. In order to preserve a balanced panel, a country was included in the data set only if observations were recorded for every year. ${ }^{7}$ Some of the shortcomings of the data set (especially with regards to developing countries) are discussed in Summers and Heston (1991).

The member countries of the SACU (established 1969) are Botswana, Lesotho, Namibia, Swaziland and South Africa. The member countries of the SADC (established 1992) are Angola, Botswana, the Democratic Republic of Congo, Lesotho, Malawi, Mauritius, Mozambique, Namibia, Seychelles, South Africa, Swaziland, Tanzania, Zambia, and Zimbabwe. For these groups convergence is only tested for G, OPEN, RGDPL, and RGDPW.

\section{EMPIRICAL RESULTS}

All estimation and testing was done in GAUSS using COINT 2.0.

\section{Lag order and unit root testing}

As the construction of the IPS test (as well as ADF unit root tests in general) depend on specifying the correct lag order of the series involved, Table 1 provides a summary of lag orders as well as the data availability for each series by country. The appropriate lag order was selected according to the procedure in Campbell and Perron (1991). Both the panel results and individual country results for the unit root tests are given in Table 2. In the case of the individual series, only rarely did the ADF test reject the null hypothesis of nonstationarity. Thus it is not surprising that even with the panel IPS test, none of the series were able to reject the null hypothesis. For the further purposes of the study, the variables are treated as $I(\mathrm{l}) .^{8}$

\section{Cointegration testing}

The cointegration testing results are given in Table 3. Overall, there is extremely strong evidence to reject long run relationships across all club leaders. The only exception is in the case of South Africa and the variable for the OPENNESS of the economy. In this case, there is a long run relationship as the pooled ADF test rejects at the $1 \%$ level. All other club leaders reject convergence for this variable. Thus, although not always at issue, it is clear that the choice of a club leader can impact the results of the testing.

In nine cases, both panel tests reject the null hypothesis. A breakdown of the results and 'sub-convergence clubs' for $G$, OPEN, and RGDPL are given in Table $4 .{ }^{9}$ Subclubs are not reported for STLIV and KAP $W$ as the original set of countries is much smaller, only 11 countries in both cases. These clubs were chosen if the single pair-wise ADF test rejected the null hypothesis at the $10 \%$ level. In the case of government spending two clubs are formed around Mauritius and Nigeria. In both cases, the clubs include the other leader and the Ivory Coast and Kenya. Unfortunately, there seems to be little more to say about why these clubs might form as there seems to be little to tie the countries on the lists together. In the case of openness, only the leader, the Ivory Coast, forms a group and again there seems to be little intuition about the other members. The result for RGDPL is a bit more interesting as convergence there, with South Africa as a leader, includes both Malawi and Zimbabwe, both members of the SADC.

Also reported in Table 3 are the averages of the beta coefficients of the test results. Comparisons can be made between these and the hypothesized value of 1 used to difference the variables. In 24 out of the 36 tests, the average coefficient is positive and less than 1 . In three cases, the coefficient is negative and less than one and in the remaining cases the coefficient is negative and less than one in absolute value.

\footnotetext{
${ }^{7}$ With nonstationary testing in panel data, it has been shown that the time dimension has a much greater impact than the cross-section dimension, on the margin, to the power of the tests. For example, see McCoskey and Kao (2000). Thus although there was some data available for certain countries for certain years, selection was ultimately based on maximizing the time dimension of the panel without eliminating too many countries.
}

\footnotetext{
${ }^{8}$ For these variables, an $I(2)$ process does not seem realistic given past economic performance.

${ }^{9}$ The individual series asymptotic critical values are given in Shin (1994) and Phillips and Ouliaris (1990). For the LM test the values are 0.231 and 0.314 for $10 \%$ and $5 \%$ respectively; for ADF the values are -3.0657 .
} 
Table 1. Data availability and estimated lag order

\begin{tabular}{|c|c|c|c|c|c|c|}
\hline & $G$ & $K A P W$ & $O P E N$ & $R G D P L$ & $S T L I V$ & $R G D P W$ \\
\hline Angola & $\mathrm{x}$ & $\mathrm{x}$ & 1 & 2 & $\mathrm{x}$ & 2 \\
\hline Benin & 1 & $\mathrm{x}$ & 1 & 1 & $\mathrm{x}$ & 1 \\
\hline Botswana & $\mathrm{x}$ & 3 & 1 & 4 & $\mathrm{x}$ & 4 \\
\hline Burkina Faso & 1 & $\mathrm{x}$ & 1 & 1 & $\mathrm{x}$ & 1 \\
\hline Burundi & 2 & $\mathrm{x}$ & 2 & 1 & $\mathrm{x}$ & 1 \\
\hline Cameroon & 1 & $\mathrm{x}$ & 1 & 2 & 1 & 5 \\
\hline Chad & 1 & $\mathrm{x}$ & 1 & 1 & $\mathrm{x}$ & 1 \\
\hline Comoros & 1 & $\mathrm{x}$ & 1 & 2 & $\mathrm{x}$ & 4 \\
\hline Congo & 1 & $\mathrm{x}$ & 1 & 3 & $\mathrm{x}$ & 3 \\
\hline Djibouti & $\mathrm{x}$ & $\mathrm{x}$ & $\mathrm{x}$ & $\mathrm{x}$ & $\mathrm{x}$ & $\mathrm{x}$ \\
\hline Ethiopia & $\mathrm{x}$ & $\mathrm{x}$ & $x$ & $\mathrm{x}$ & $\mathrm{x}$ & $x$ \\
\hline Gabon & 1 & $\mathrm{x}$ & 5 & 2 & 1 & 2 \\
\hline Gambia & 1 & $\mathrm{x}$ & 3 & 3 & $\mathrm{x}$ & 3 \\
\hline Ghana & 1 & $\mathrm{x}$ & 2 & 1 & 3 & 1 \\
\hline Guinea & 1 & $\mathrm{x}$ & 1 & 1 & $\mathrm{x}$ & 1 \\
\hline Ivory Coast & 2 & 2 & 1 & 1 & 1 & 1 \\
\hline Kenya & 1 & 2 & 1 & 1 & 3 & 1 \\
\hline Lesotho & 1 & $\mathrm{x}$ & 1 & 1 & $\mathrm{x}$ & 1 \\
\hline Liberia & $\mathrm{x}$ & $\mathrm{x}$ & $\mathrm{x}$ & $\mathrm{x}$ & $x$ & $\mathrm{x}$ \\
\hline Madagascar & 1 & 2 & 1 & 1 & $\mathrm{x}$ & 1 \\
\hline Malawi & 1 & 2 & 1 & 4 & 1 & 4 \\
\hline Mali & 1 & $\mathrm{x}$ & 1 & 1 & 0 & 1 \\
\hline Mauritania & 2 & $\mathrm{x}$ & 2 & 1 & $\mathrm{x}$ & 1 \\
\hline Mauritius & 1 & 4 & 1 & 1 & 1 & 1 \\
\hline Mozambique & 4 & $\mathrm{x}$ & 3 & 2 & $\mathrm{x}$ & 2 \\
\hline Namibia & 1 & $\mathrm{x}$ & 1 & 1 & $\mathrm{x}$ & 1 \\
\hline Niger & $\mathrm{x}$ & $\mathrm{x}$ & 1 & 5 & $\mathrm{x}$ & 5 \\
\hline Nigeria & 1 & 4 & 1 & 2 & 1 & 2 \\
\hline Reunion & $\mathrm{x}$ & $\mathrm{x}$ & 3 & 1 & $\mathrm{x}$ & 1 \\
\hline Rwanda & 1 & $\mathrm{x}$ & 1 & 1 & $\mathrm{x}$ & 1 \\
\hline Senegal & 1 & $\mathrm{x}$ & 1 & 0 & 1 & 1 \\
\hline Seychelles & 3 & $\mathrm{x}$ & 1 & 1 & $\mathrm{x}$ & 2 \\
\hline Sicrra Lcone & $\mathrm{x}$ & 1 & $\mathrm{x}$ & $\mathrm{x}$ & $x$ & $\mathrm{x}$ \\
\hline Somalia & $\mathrm{x}$ & $\mathrm{x}$ & 4 & 1 & $\mathrm{x}$ & 1 \\
\hline South Africa & 1 & $\mathrm{x}$ & 2 & 1 & 1 & 1 \\
\hline Sudan & $x$ & $\mathrm{x}$ & $x$ & $\mathrm{x}$ & $\mathrm{x}$ & $\mathrm{x}$ \\
\hline Swaziland & $\mathrm{x}$ & 2 & 1 & 1 & $\mathrm{x}$ & 1 \\
\hline Tanzania & $\mathrm{x}$ & $\mathrm{x}$ & $\mathrm{x}$ & $\mathrm{x}$ & $\mathrm{x}$ & $\mathrm{x}$ \\
\hline Togo & 5 & $\mathrm{x}$ & 1 & 1 & $\mathrm{x}$ & 1 \\
\hline Uganda & 1 & $\mathrm{x}$ & 3 & 3 & $\mathrm{x}$ & 3 \\
\hline Zaire & $\mathrm{x}$ & $\mathrm{x}$ & 3 & 5 & $\mathrm{x}$ & 5 \\
\hline Zambia & 1 & 2 & 5 & 1 & $\mathrm{x}$ & 1 \\
\hline Zimbabwe & 1 & 2 & 1 & 1 & $\mathrm{x}$ & 1 \\
\hline
\end{tabular}




\section{IPS unit root testing on the differences}

The IPS test is again used to test the stationarity of the differences of the series. In this case, no leader is specified and ADF test statistics are computed for each possible combination of countries. In this case, all countries can be treated symmetrically. The lag order for the ADF tests and criteria for selection of the mean and variance for the test, are taken to be the maximum lag order for the set of countries reported in Table 1 for the relevant variable. The results are given in Table 5. The average $t$-statistic for the ADF test, the IPS z-bar, the $p$-value on the z-bar and the number of pair-wise combinations in the set are reported.

In this case, both OPEN and STLIV can reject the null of nonstationarity of differences, or the null hypothesis of nonconvergence, at the $10 \%$ level with $p$-values of 0.0793 and 0.0681 respectively. Neither of the income variables (RGDP based) nor the KAPW can reject the null hypothesis.

In the case of OPEN, the convergence is interesting in that it signals, perhaps, some continental commonality. This would seem to bode well for intra continental trade agreements and the opening of borders to trade. The result for STLIV is also interesting, although the original set of countries is quite small: Cameroon, Gabon, Ghana, Ivory Coast, Kenya, Malawi, Mali, Mauritius, Nigeria, Senegal, and South Africa. Seven countries in this group are clustered in West Africa. The four others are geographically dispersed around central and southern Africa. This variable, STLIV, was added to the Penn World tables as part of the updates for version 5.6 and is an attempt to measure wellbeing more accurately than with using RGDP. It measures the amount spent (both privately and through government) per capita rather than gross earnings per capita. Thus, there is some evidence of convergence in well being, albeit for a small, subset of countries. It is possible that the mere fact that data is available for this variable may indicate the relative development of these countries (i.e. resources available for stable data collection) and therefore this group makes an especially coherent club. Note that with the establishment of a coherent club, the suitability of introducing another country into the club could be tested using the entrant as the leader and then pooling the results comparing the leader to each member using the IPS test.

\section{Unit root tests for SACU and SADC}

Finally, the IPS test on the difference of series was also done for the subsets of SACU and SADC countries. In this case, only $G$, $R G D P L$, and RGDPW were tested as OPEN and STLIV already tested positive for convergence and KAP W did not have data available for many of the countries. The results are given in Tables 6 and 7. A priori one might expect these groups to display convergence given the geographic proximity and the willingness of the countries themselves to enter into such official agreements. The data does not extend beyond 1990 and for that reason some more recent developments within the agreements cannot be captured. Again all possible pair-wise combinations are used so that each country is treated symmetrically. The tests were constructed using both three and five lags.

In no case, for either SACU or SADC countries could convergence be found. The closest to rejecting no convergence was RGDPL for the case of three lags for the SACU countries. That test had a one-tailed $p$-value of 0.1151 . Overall, despite an increased number of members for the SADC, the p-values on the z-bar statistics were much higher than those for the SACU countries. Country differences within the Southern Africa region, at least during the time of the data series, seem not to be disappearing. It would be interesting to see if these results change as the two organizations continue their cooperative strategies.

\section{Structural breaks}

One very real econometric issue to consider when interpreting the results is the fact that all the tests are based on individual test statistics. These test statistics can be misleading if there is a structural break in the data. A test for unit roots in the presence of structural breaks is discussed in Perron (1989). Pretorius and McCoskey (2000) investigate this issue further when unit root tests are conducted on small data samples with structural breaks. They report results on the bias structural breaks introduce to tests of the null hypothesis of nonstationarity (toward non-rejection of the null). In addition, they report the size distortions (not power) structural breaks introduce to tests constructed under the null hypothesis of stationarity. Thus if individual series contain breaks, this could impact the aggregated, panel results. 
Table 2. Individual country $A D F$ and IPS unit root results

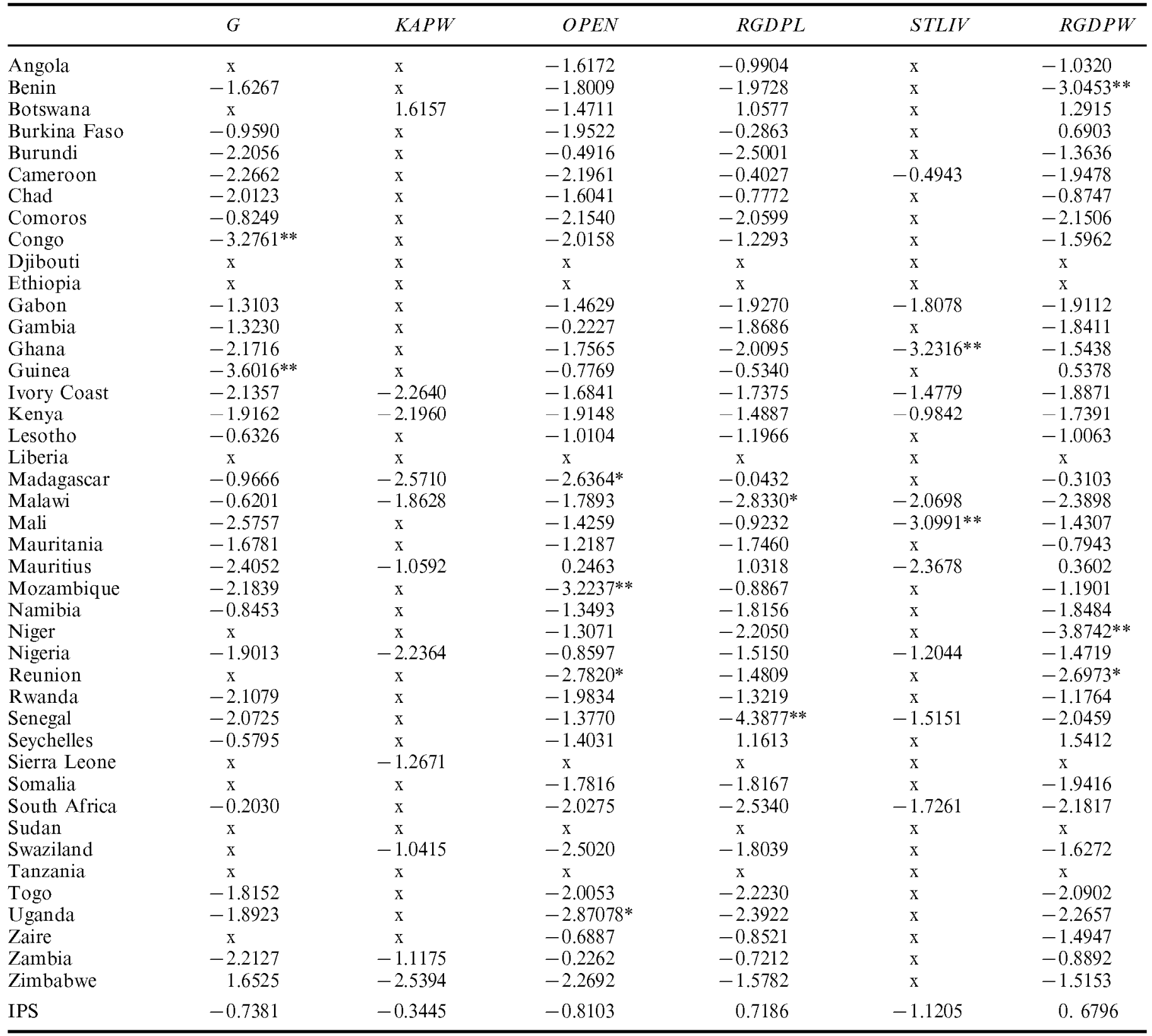

Note: Rejection rates for ADF taken from COINT: -2.9371 for $5 \%(* *)$ and -2.6152 for $10 \%(*)$. IPS rejection rate is a one-sided standard normal value of -1.645 . 
Table 3. Panel cointegration testing results

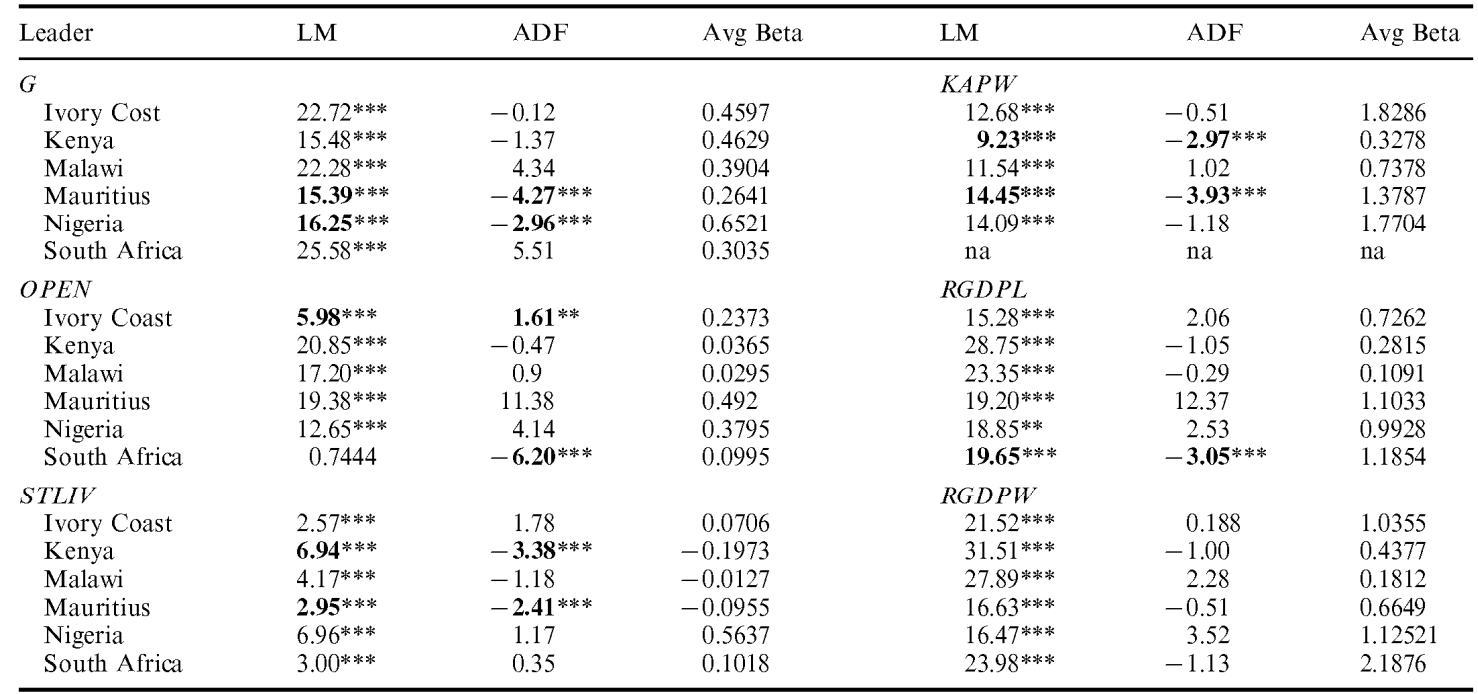

Note: Rejection values are based on one-tailed test from the standard normal distribution.

Table 4. Potential 'sub-clubs' of convergence

\begin{tabular}{llll}
\hline$G$ & & $O P E N$ & $R G D P L$ \\
\hline Mauritius & Nigeria & Ivory Coast & South Africa \\
Comoros & Ivory Coast & Comoros & Malawi \\
Ghana & Kenya & Niger & Togo \\
Ivory Coast & Mauritius & Senegal & Zimbabwe \\
Kenya & Zambia & Seychelles & \\
Mozambique & & & \\
Nigeria & & & \\
Seychelles & & & \\
\hline
\end{tabular}

Note: 'Sub-clubs' are formed from the panels in Table 3 where the panel ADF was rejected. The clubs represent the set of individual countries which can reject the ADF of no cointegration with the leader country. (Reject at $10 \%$ level.)

Table 5. IPS test for convergence of differences

\begin{tabular}{llrll}
\hline & Avg $t$-stat & $z$-bar & $p$-value & Combinations \\
\hline$G$ & -1.433 & -0.4423 & 0.1700 & 435 \\
$K A P W$ & -0.7169 & 1.7363 & 0.9582 & 55 \\
OPEN & -1.5884 & -1.4107 & 0.0793 & 666 \\
$R G D P L$ & -1.0491 & 1.7805 & 0.9625 & 666 \\
STLIV & -1.8601 & -1.4899 & 0.0681 & 55 \\
$R G D P W$ & -1.0692 & 1.6615 & 0.9515 & 666 \\
\hline
\end{tabular}

Note: $p$-values computed based on one-tailed standard normal distribution. 
Table 6. IPS unit root test results for $S A C U$ members

\begin{tabular}{|c|c|c|c|c|c|c|}
\hline & \multicolumn{2}{|l|}{$G$} & \multicolumn{2}{|l|}{$R G D P L$} & \multicolumn{2}{|l|}{$R G D P W$} \\
\hline Combinations & 3 & 3 & 10 & 10 & 10 & 10 \\
\hline
\end{tabular}

Note: Botswana and Swaziland are not included in the set for $G$.

Table 7. IPS unit root test results for SADC members

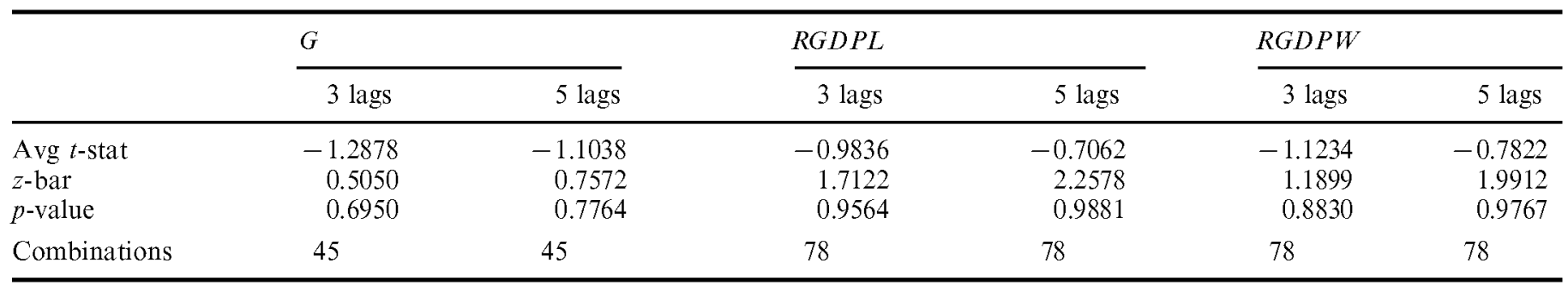

Note: Tanzania is not included for any of the variables; Angola, Botswana, and Swaziland are not included for $G$.

One possible solution is to investigate the data using the test proposed by Perron. However, in this paper there are two difficulties with that approach. First, the Perron test is for the strict time series case, no panel form exists. In fact, as the critical values depend on the placement of the break (with respect to the total time dimension of the data) there is, with panel data, the crucial question as to whether all breaks in the data must occur at the same point. However, individual time series could be reported to add some insights to the study. The second difficulty turns out to be more serious with respect to the study here: all three forms of the Perron test test the null hypothesis of nonstationarity versus the alternative of trend stationary with a structural break. As discussed previously, trend stationarity is not the appropriate alternative hypothesis for the convergence argument. Under the Perron construction, both the null and alternative imply nonconvergence.

In this paper, as unit root tests are based on differences, some possibilities with respect to structural breaks should be mentioned. If all or many countries in the study are subject to similar structural breaks, then the series of differences should not contain a break. Thus, regional or continent-wide shocks need not impact the results. If only several countries experience breaks during the sample, then while there may be some bias, there may be enough other combinations in the data set to mute the impact on the final test statistic.

To investigate whether breaks may have impacted the panel results, one data series, $R G D P L$ was considered country by country to see which may have experienced a break. Ten countries were identified with possible structural breaks: Angola (1974-1975), Comoros (1974-1975), Gabon (1976), Gambia (1978), Ivory Coast (1979), Mauritania (1976), Mozambique (1973), Namibia (1979), Swaziland (1981) and Uganda (1983). The data of the RGDPL series for these countries are given in Table 8. The IPS test for $R G D P L$ was re-calculated excluding these countries. Thus, 27 countries were included (351 combinations). Tests were run using five and then three lags. In neither case did the omission of the countries with a potential break impact the results: for three lags the z-bar was 1.9433 and for five lags, 2.697. Both are further from rejection than the test statistic with the complete sample, 1.7805 ( $p$-value of 0.9625 ). Given these results, for the three test results which were the furthest from rejecting nonconvergence, $K A P W$, $R G D P L$, and $R G D P W$, it seems unlikely that structural breaks are causing the nonrejection. Rather, fundamentally different paths of the development of income variables across countries seem to be at the source of the nonconvergence.

Clearly, in the panel context, more research needs to be done on structural breaks. Important questions about the required degree of homogeneity for the breaks across the panel certainly need to be investigated. There are however, several papers which at least discuss the issues involved, Kao and Chiang (2000) and Emerson and Kao (2000).

\section{CONCLUSION}

In this paper panel data tests for unit roots and cointegration are used to investigate the convergence properties of six indicators of 
well being in Sub-Saharan Africa. This follows from the recent literature that global convergence may not be feasible whereas 'club' convergence may still occur. Treating Sub-Saharan Africa as a club in and of itself is perhaps misguided. Intra and inter-regional deviations may be too great, an idea supported by the lack of convergence in the results.

In the cointegration, leader-based testing, there is little evidence of long run relationships with regards to the income based, or $R G D P$ based, variables. The one exception is the real GDP per capital and the subclub of leader South Africa and Malawi, Togo and Zimbabwe. In addition using South Africa as the leader country, cointegration was found with regards to openness of the economy.

In the more complete IPS unit root tests for convergence across the sample, both OPEN and STLIV rejected the null hypothesis of no convergence. Again the RGDP-based variables showed no evidence of convergence. Finally, for the SACU and SADC countries again no convergence was found for the $G, R G D P L$ and $R G D P W$ variables.

However, the use of panel data tests to investigate convergence properties offers several advantages over the strict time series case. Of course, pooling test results increases the power of the test. In addition, allowing for all possible combinations makes it unnecessary to choose a leader country. Such a choice may lead to misleading results. Panel tests could also be used to consider whether an individual country could be added to an already stable convergence club by pooling information across all previous club members. Thus, if one accepts the stationarity argument as a measure of convergence, panel tests should allow the direct testing of convergence clubs.

\section{ACKNOWLEDGEMENTS}

Special thanks to the Council for International Exchange of Scholars (CIES) and the South African Fulbright Commission for their support. Thanks also to participants in the Fifth Annual African Econometric Modeling Conference, the author's fellow econometricians at the University of Pretoria, and an anonymous referee.

Table 8 . Countries with potential break points in RGDPL

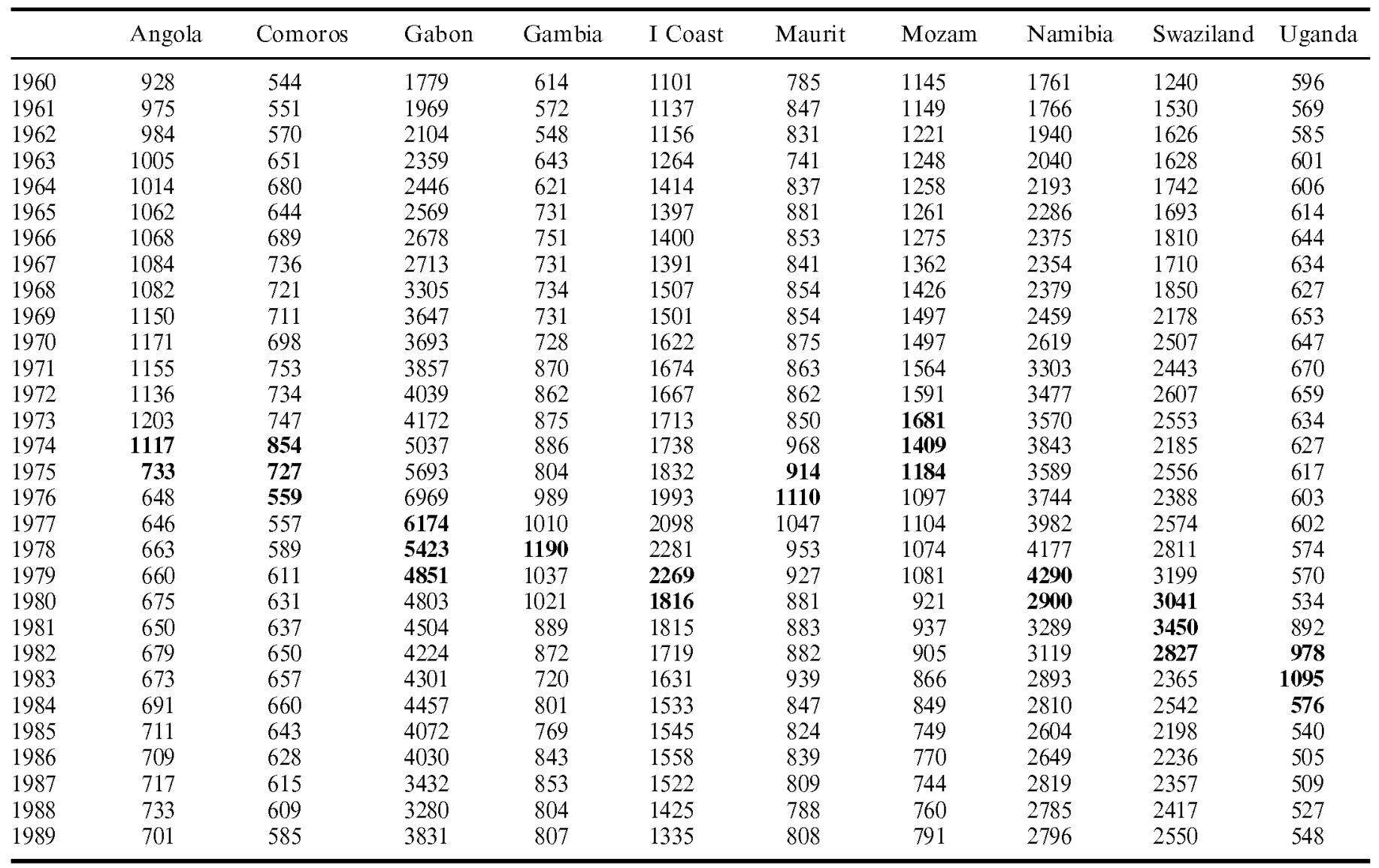

Note: Potential break periods are highlighted in bold type. 


\section{REFERENCES}

Barro, R. J. (1991) Economic growth in a cross section of countries, Quarterly Journal of Economics, 106, 407-43.

Barro, R. J. and Sala-I-Martin, X. (1991) Convergence across states and regions, Brookings Papers on Economic Activity, 107-82.

Barro, R. J. and Sala-I-Martin, X. (1992) Convergence, Journal of Political Economy, 100, 223-51.

Barro, R. J. and Sala-I-Martin, X. (1995) Economic Growth, McGraw-Hill, New York.

Baumol, W. (1986) Productivity growth, convergence, and welfare: what the long-run data show, American Economic Review, 76, 1155-9.

Campbell, J.Y. and Perron, P. (1991) Pitfalls and opportunities what macroeconomists should know about unit roots, in NBER: Macroeconomics Annual (Eds) O. J. Blanchard and S. Fischer, National Bureau of Economic Research, Cambridge, MA, MIT Press, $141-201$.

Durlauf, S. and Johnson, P. (1992) Local versus global convergence across national economies, NBER Working Paper, No. 3996.

Emerson, J. and Kao, C. (2000) Estimating and testing for structural change for GDP growth rates in panel data, Working Paper, Syracuse University.

Harris, D. and Inder, B. (1994), A Test of the null hypothesis of cointegration, in Non-stationary Time Series Analysis and Cointegration (Ed.) C. Hargreaves, Oxford, Oxford University Press, 133-52.

Im, K. S., Pesaran, M. H. and Shin, Y. (1997) Testing for unit roots in heterogeneous panels, Working Paper, Department of Applied Economics, University of Cambridge.

Islam, N. (1995) Growth Empirics: a panel data approach, Quarterly Journal of Economics, 110, 1127-70.

Kao, C. and Chiang, M. H. (2000) Testing for structural change of a cointegrated regression in panel data, Working Paper, Syracuse University.

Lee, K., Pesaran, M. H. and Smith, R. (1997) Growth and convergence in a multi-country empirical stochastic Solow Model, Journal of Applied Econometrics, 12, 357-92.

Mankiw, N. G., Romer, D. and Weil, D. N. (1992) A contribution to the empirics of economic growth, The Quarterly Journal of Economics, 40737.

McCoskey, S. and Kao, C. (1998) A residual-based test of the null of cointegration in panel data, Econometric Reviews, 17, 57-84.

McCoskey, S. and Kao, C. (1999) Testing the stability of a production function with urbanization as a shift factor, Oxford Bulletin of Economics and Statistics, 61, 671-90.

McCoskey, S. and Kao, C. (2000) A Monte Carlo comparison of tests for cointegration in panel data (with an application to the twin deficits problem), Working Paper, Syracuse University.

Pedroni, P. (1997) On the role of human capital in growth models: evidence from a nonstationary panel of developing countries, Working Paper, Indiana University.

Penn World Tables, Computing in the Humanities and Social Sciences (CHASS), University of Toronto, http://datacentre2.chass.utoronto.ca/pwt/index.html.

Perron, P. (1989) The great crash, the oil price shock and the unit root hypothesis, Econometrica, 57, 1361-401.

Phillips, P. C. B. (1986) Understanding spurious regressions in econometrics, Journal of Econometrics, 33, 311-40.

Phillips, P. C. B. and Ouliaris, S. (1990) Asymptotic properties of residual based tests for cointegration, Econometrica, 58, $165-93$.

Pretorius, E. and McCoskey, S. (2000) Misdiagnosing structural breaks and the small sample unit root tests: does the South African economy really walk randomly? Working Paper, University of Pretoria.

Quah, D. T. (1993) Empirical cross-section dynamics in economic growth, European Economic Review, 37, 426-34.

Quah, D. T. (1996a) Convergence as distribution dynamics (with or without growth), Center for Economic Performance Discussion Paper, No. 317.

Quah, D. T. (1996b) Convergence empirics across economies with (some) capital mobility, Journal of Economic Growth, 1, 95-124.

Quah, D. T. (1996c) Empirics for economic growth and convergence, European Economic Review, 40, 1353-75.

Sala-I-Martin, X. (1996) Regional cohesion evidence and theories of regional growth and convergence, European Economic Review, 40, $1325-52$.

Shin, Y. (1994) A residual-based test of the null of cointegration against the alternative of no cointegration, Econometric Theory, $10,91-115$.

St. Aubyn, M. (1999) Convergence across industrialized countries (1890-1989): new results using time series methods, Empirical Economics, 24, 23-44.

Summers, R. and Heston, A. (1991) The Penn World Tables (Mark 5): An expanded set of international comparisons, 1950-1998, Quarterly Journal of Economics, 106, 327-68. 